\title{
Mixing in Downslope Flows in the Ocean - Plumes versus Gravity Currents
}

\author{
Peter G. Baines* \\ QUEST, Department of Earth Sciences, Bristol, UK and \\ Department of Civil and Environmental Engineering \\ University of Melbourne, Australia 3010
}

[Original manuscript received 28 November 2007; accepted 8 March 2008]

\begin{abstract}
The nature of downslope flows into stratified environments as revealed by laboratory experiments is described, and the results are then applied to interpret particular downslope flows into the ocean. In the laboratory, non-rotating downslope flows can be divided into two main types: detraining gravity currents over sufficiently gentle slopes, where the buoyancy force of the dense downflow is mainly balanced by bottom drag, and entraining plumes over sufficiently steep slopes, where the buoyancy force is balanced by vigorous entrainment of environmental fluid from above. This mixing character of the flow is determined by the bottom slope, the drag coefficient and the buoyancy number $B=Q N^{3} / G^{2}$, where $Q$ and $G$ are the volume flux and buoyancy of the downflow and $N$ is the buoyancy frequency of the environment. These experiments may be applied to situations in the ocean where the flow is in approximate geostrophic balance with its transverse pressure gradient, and the parameters are applied to the flow path on the slope. Examples are provided for a number of downslope flows in various locations, including the Red Sea outflow, the Mediterranean outflow into the Black Sea and the Atlantic, the Denmark Strait overflow and the outflow from the Ross Sea.
\end{abstract}

RÉSUMÉ [Traduit par la rédaction] Nous décrivons la nature des écoulements descendants dans les environnements stratifiés en nous basant sur des expériences en laboratoire et nous nous servons ensuite des résultats pour interpréter certains écoulements descendants dans l'océan. Au laboratoire, on peut regrouper les écoulements descendants non rotatifs en deux grandes catégories : les courants de gravité détraînants le long de pentes suffisamment faibles, où la force hydrostatique du courant descendant est principalement équilibrée par la force de traînée contre le fond, et les panaches entraînants le long de pentes suffisamment fortes, où la force hydrostatique est équilibrée par un vigoureux entraînement du fluide environnemental au-dessus. L'importance de ce mélange de l'écoulement est déterminée par la pente du fond, le coefficient de traînée et le nombre de flottabilité $B=Q N^{3} / G^{2}$, où $Q$ et $G$ sont le flux volumique et la flottabilité de l'écoulement descendant et $N$ est la fréquence de flottabilité de l'environnement. Ces expériences peuvent s'appliquer dans un contexte océanique où l'écoulement est approximativement en équilibre géostrophique avec son gradient de pression transversal et les paramètres sont appliqués au trajet de l'écoulement le long de la pente. Nous donnons des exemples pour un certain nombre d'écoulements descendants en divers endroits, y compris la sortie de la mer Rouge, la sortie de la Méditerranée dans la mer Noire et dans l'Atlantique, les eaux de débordement du détroit du Danemark et la sortie de la mer de Ross.

\section{Introduction}

The flow of dense fluid down slopes occurs in many locations in the ocean and is generally accompanied by local small-scale mixing that affects the behaviour on larger scales (Turner, 1973). These mixing properties and flow structure are strongly affected by the stratification of the environment into which they descend and differ significantly from dense flows into homogeneous fluids. The purpose of this paper is twofold. The first purpose, in Section 2, is to provide a summary of the results of laboratory experiments on two-dimensional downslope flows into non-rotating stratified environments where the stratifica- tion is large enough to affect the behaviour of the downflow. These experiments are described in detail in Baines (2001, 2002, 2005). The second, in Section 3, is to apply these results to infer the mixing properties of downslope flows at specific locations in the ocean. Five locations are examined, namely the outflow of dense fluid from the Red Sea, flow down the continental slope from the western part of the Ross Sea, the Denmark Strait overflow, the inflow from the Bosphorus into the Black Sea and the Mediterranean outflow into the Atlantic Ocean. The conclusions are summarized in Section 4.

*Author's e-mail: p.baines@unimelb.edu.au 


\section{The nature of dense downslope flows into stratified environments, as inferred from laboratory experiments}

The properties of downslope flows descending under their own buoyancy into density-stratified environments have been studied with a number of laboratory experiments by the author. The most complete descriptions of these studies are presented in Baines (2001, 2002, 2005), and the results are summarized here; earlier versions were presented in Mitsudera and Baines (1994) and Baines (1999). These experiments were all two-dimensional in the mean and were non-rotating. They were carried out in a tank of approximately $3 \mathrm{~m}$ in length but arranged so that the effective length was somewhat longer. In each experimental run, the tank was filled with a uniformly salt-stratified fluid and the dense inflow was maintained at a constant rate so that the flow reached a steady state in the mean. This steady state was maintained for a suitably long period of time so that the properties of this mean flow could be measured and recorded. A wide range of flow conditions was covered. In particular, the slope angle $\theta$, the volume inflow rate $Q$ (per unit width) at the top of the slope, the buoyancy frequency $N$ of the stratification, the buoyancy $g^{\prime}$ of the inflow and the bottom roughness were all varied in these experiments. The Reynolds number of the flow always exceeded values of several hundred, guaranteeing that the flows were predominantly turbulent.

These experiments showed that downslope flows into stratified environments could be divided into two main types of flow which may be termed gravity currents and plumes, respectively. Under certain conditions there is also a third type which fits neither of these types, as described later in this section. The term 'gravity current' is commonly used to describe dense fluid spreading over horizontal surfaces (Baines, 1995; Simpson, 1997). Gravity currents over horizontal surfaces generally begin with a prominent 'head' which leads the flow and entrains part of the environmental fluid into the current immediately behind it, but once the head passes there is relatively little mixing and entrainment between the current and the fluid above. Flows down slopes also begin with a similar head structure that increases in size with slope angle (Britter and Linden, 1980). Flows on gentle slopes may also be termed 'gravity currents' and are contiguous with the horizontal state, but they have different properties that become more prominent with increasing slope angle. Flows down vertical slopes are generally termed 'plumes' (two-dimensional ones in this situation). These flows have properties that are generally similar to those of flows emerging from (for example) an inverted chimney - the flow is conspicuously turbulent, and it entrains fluid from the environment into the downflow, increasing the downward mass transport and decreasing the mean density contrast until a neutral buoyancy level is reached (or passed) in the stratification. Flows down very steep slopes have a similar character to those on vertical slopes and are also termed 'plumes'. For most slope angles between zero and the vertical, the experiments show that most flows can be classified as either gravi- ty currents, or plumes, with a relatively narrow boundary region in between. The parameter ranges in which these flow states occur are termed the gravity current and plume regimes respectively, and the properties of these flow regimes are now described in some detail.

\section{a The Gravity Current Regime(1)}

Figure 1 shows the development of a flow in the gravity current regime over a slope of $12^{\circ}$ to the horizontal. The incoming dense fluid has been dyed with fluorescene and illuminated by a thin laser beam, scanned along a central vertical section. The brightest fluid adjacent to the bottom is the dense bottom current, and it has a reasonably distinct upper boundary. Near the top of the slope there is an initial adjustment region in which this dense fluid adjusts to a state of approximately constant thickness, which it maintains for most of the downflow until it approaches its level of neutral density. Here it thickens and separates from the slope to form an intrusion into the stratified environment, with no suggestion of an overshoot past this level. However, it is also clear from Fig. 1 that some dyed fluid has left the dense boundary current and has been detrained and mixed into the environment, where it sits above the current. This has been achieved by small-scale mixing events that arise from shear flow instability but are less vigorous than Kelvin-Helmholtz billows and have the character of Holmboe waves of finite amplitude (this is most clearly evident in experiments with small slope angles, such as $3^{\circ}$ ). In these eddying motions (in the vertical plane) the velocity is more vigorous above the density interface of the current than within it, and small wisps of dense fluid may be seen being swept off the top of the current and mixed into the environmental fluid, producing a net result of dense fluid being detrained from the current. This occurs along most of the length of the current, the exceptions being the adjustment region at the top of the slope and the intrusion region at the bottom at the neutral buoyancy level. In all of the experimental runs which produced gravity currents, the level of the intrusion at the bottom of the downflow was slightly higher than the level expected from the density of the inflow at the top of the slope. This implies that in addition to the conspicuous detrainment evident in Fig. 1, there was also some entrainment of the stationary environmental fluid into the downflow, producing a slight decrease in its density. In summary, these flows in the 'gravity current regime' are characterized by the following properties: the downflow has a distinct upper boundary, or interface, with approximately uniform thickness $d$; the fluid leaves the slope as an intrusion at its neutral level, with negligible overshoot and spring-back; the principal dynamical balance is between buoyancy and drag from above and below, but principally bottom drag (see later in this section); and detrainment to the overlying fluid dominates over entrainment from it, though both processes occur. This pattern of flow was first described by Mitsudera and Baines (1994).

The dynamics of these gravity currents may be described in terms of a single layer model of the downflow. Interactions 

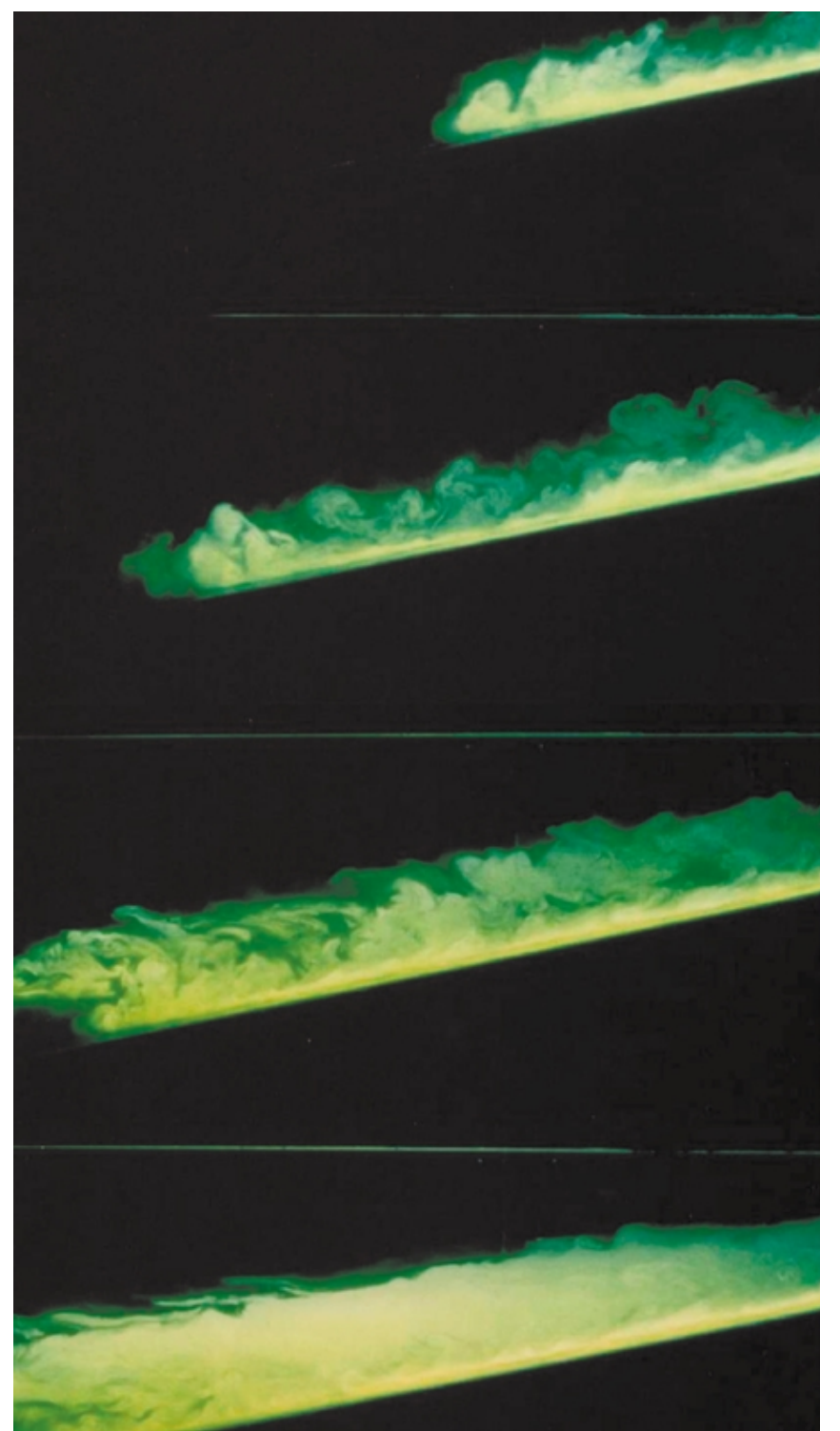

Fig. 1 The time sequence of the development of a flow with the character of a gravity current on a slope of $12^{\circ}$, with $B_{0}=0.0058$. The incoming fluid has been dyed with fluorescene and is illuminated by a thin laser beam that scans a central vertical section. The first two frames show the leading gravity current head, and the last frame is taken at a much later time than that of the other three, where the bottom current is in steady state. The lowest three frames show the accumulation of detrained fluid above the downflow.

with the bottom surface of the slope are represented by a quadratic drag force with a drag coefficient $C_{D}$, and interactions with the stratified fluid above by a detrainment coefficient and an entrainment coefficient, representing the asymmetric two-way flux of fluid across the interface. (The drag of the overlying fluid is generally much less than (typically $10 \%$ of) the drag on the rigid bottom; it may be ignored in the discussion, or $C_{D}$ may be taken to be the total drag coefficient for upper and lower surfaces.) The variables are depicted in Fig. 2. The buoyancy, $G$, and buoyancy frequency, $N$, are defined by:

$$
G=g^{\prime}(z)=\frac{g \Delta \rho(z)}{\bar{\rho}_{0}}, \quad N^{2}=-\frac{g}{\bar{\rho}_{0}} \frac{d \rho_{0}(z)}{d z},
$$

where $z$ is the vertical coordinate, $\rho_{0}(z)$ is the density of the ambient stratification with $\bar{\rho}_{0}$ a representative mean value, $g$ denotes the acceleration due to gravity, and $\Delta \rho(z)$ denotes the difference between density in the downflow and the mean local ambient density of the environment. Other relevant variables are the bottom slope $\theta$, the two-dimensional volume flow rate $Q$, the thickness, $d$, of the downflow normal to the slope with temporal mean value $\bar{d}$, the mean velocity $U=Q / \bar{d}$, and the drag coefficient, $C_{D}$. An important dimensionless parameter in these flows is the Buoyancy number $B$, defined by

$$
B=\frac{Q N^{3}}{G^{2}},
$$

which relates the properties of the downflow to the stratification and varies with downslope position because $Q$ and $G$ vary with $z$. At the top of the slope where $z=0$, the value of $B(0)$ is denoted by $B_{0}$, and this variable and the slope angle, $\theta$, are the principal parameters used to characterize the flow. In these experiments and in the ocean, $B$ takes values that are mostly in the range $0.001-0.1$. Other relevant parameters are the Reynolds number Re and the Richardson number Ri, defined by:

$$
\operatorname{Re}=\frac{Q}{v}, \quad \operatorname{Ri}=\frac{G \bar{d}^{3} \cos \theta}{Q^{2}},
$$

where $v$ is the fluid viscosity.

In terms of the above variables, equations for the downflow may be derived in the form (see Baines, 2001)

$$
\begin{gathered}
\frac{\partial \bar{d}}{\partial t}+\frac{\partial Q}{\partial s}=\left(E_{e}-E_{d}\right) \frac{Q}{\bar{d}}, \\
\frac{\bar{d}}{Q} \frac{\partial G}{\partial t}+\frac{\partial G}{\partial s}=-N^{2} \sin \theta-E_{e} G / \bar{d}, \\
\frac{\partial Q}{\partial t}+\frac{\partial}{\partial s}\left(\frac{Q^{2}}{\bar{d}}\right)=G \bar{d} \sin \theta-C_{D} \frac{Q^{2}}{\bar{d}^{2}}-\frac{\cos \theta}{2} \frac{\partial}{\partial s}\left(\bar{d}^{2} G\right),
\end{gathered}
$$

where $s$ denotes downslope distance from the top of the slope, with $z=-s \sin \theta$. Note that the drag coefficient applies to the mean velocity of the layer. For the purposes of interpreting these experiments, it is appropriate to assume that the flow is locally steady and omit the temporal derivatives. Equations (4) to (6) may then be expressed as

$$
\begin{gathered}
\frac{\mathrm{d} Q}{\mathrm{~d} s}=\left(E_{e}-E_{d}\right) \frac{Q}{\bar{d}}, \\
\frac{\mathrm{d} G}{\mathrm{~d} s}=-N^{2} \sin \theta-E_{e} G / \bar{d},
\end{gathered}
$$




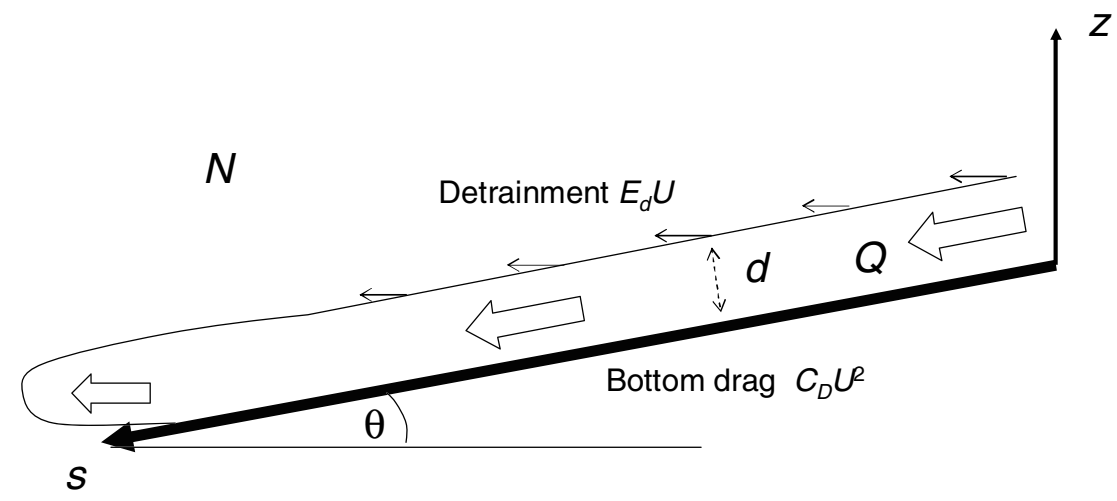

Fig. 2 Schematic depiction of an experimental flow of a gravity current with significant variables, where $Q=d U$.

$$
\begin{gathered}
(1-\operatorname{Ri} \cos \theta) \frac{\mathrm{d} \bar{d}}{\mathrm{~d} s}=2 E_{e}+C_{D}-E_{d} \\
-\operatorname{Ri}\left(\sin \theta+\frac{E_{e} \cos \theta}{2}+\frac{\sin \theta}{2}\left(\operatorname{Ri} B^{2} \cos ^{2} \theta\right)^{1 / 3}\right) .
\end{gathered}
$$

In the experiments, all the terms in Eq. (7) may be measured as functions of $z$, except for $E_{e}$ and $E_{d}$. The result is that, except for the initial adjustment region near the top of the slope and the region near the intrusion at the bottom of the downflow, $E_{d}-E_{e}$ may be expressed in terms of $\theta$ and the local value of $B$, and the best simple fit to the data gives (Baines, 2001):

$$
E_{d}=E_{e}+0.2 B^{0.4} \sin \theta .
$$

This relationship holds quite well for bottom slopes up to at least $12^{\circ}$; it is less satisfactory for steep slopes of $20^{\circ}$ or more, but still gives a reasonable first approximation in the central detraining region (Baines, 2005). From different considerations one may deduce that $E_{e}$ should have the form (Fernando, 1991; Strang and Fernando, 2001; Baines, 2001):

$$
\begin{aligned}
E_{e} & =\frac{C_{1}(\theta)}{0.1}, \quad 0<\mathrm{Ri}<0.1, \\
& =\frac{C_{1}(\theta)}{\mathrm{Ri}}, \quad \mathrm{Ri}>0.1,
\end{aligned}
$$

where $C_{1}(\theta)$ is a function of the slope angle, with a value of $1.2 \times 10^{-4}$ for $\theta>5^{\circ}$, increasing to a value of $10^{-3}$ as $\theta \rightarrow 0$ (see Fig. 16 of Baines (2001)). The gravity current regime was observed for larger slope angles up to $30^{\circ}$ under certain conditions. As stated above, here the fit (Eq. (10)) is less accurate and is best for smaller values of $B_{0}$ (Baines, 2005), but it still gives a reasonable approximation overall. $E_{e}$ is generally much smaller than $E_{d}$, and Eq. (10) therefore gives an empirical expression for the detrainment. In general, the gravity current regime breaks down for sufficiently steep slopes, where the thickness of the current becomes small. Before discussing the criteria for this breakdown we first consider the properties of the other flow regimes.

\section{b The Plume Regime (2)}

The dynamics of the plume regime are more familiar and are essentially a two-dimensional version of those described by Morton et al. (1956). This regime is contiguous with the vertical slope case, and the flows may be appropriately described as 'plumes', as distinct from gravity currents. A photograph of a representative flow is shown in Fig. 3. Apart from an initial adjustment region at the top of the slope, the boundary current is turbulent with an upper (or outer) boundary that is vaguely defined and has conspicuous turbulent billows which entrain environmental fluid into the downflow through most of its length. At the bottom of the downflow, the current overshoots its level of neutral density and springs back in the form of a large circulating eddy to give a broad region of outflow centred on the mean neutral-density level. Some of this sprung-back fluid is re-entrained into the boundary current and re-circulated in the 'eddy' constituting the spring-back. An illustrative sketch is shown in Fig. 4. Except for the levels of the intruding outflow, the main effect on the environment is one of entrainment, causing net flow towards the slope at most levels, including the overshoot region below the intrusion. In these flows, the bottom drag is generally not significant in the momentum equation, and the downward buoyancy force is effectively balanced by the increased volume and momentum transport due to entrainment of the environmental fluid.

The model equations use most of the same variables as those for gravity currents, although the mean thickness, $\bar{d}$, is less clearly observed because of the eddying motion of the interface. As before, the experimental observations were for steady-state conditions, and the steady-state equations are (Ellison and Turner, 1959; Baines, 2005):

$$
\begin{gathered}
\frac{\mathrm{d} Q}{\mathrm{~d} s}=E U=E Q / \bar{d}, \\
\frac{\mathrm{d} G}{\mathrm{~d} s}=-N^{2} \sin \theta-\frac{E G}{\bar{d}}, \\
\frac{\mathrm{d}\left(Q^{2} / \bar{d}\right)}{d s}=S_{2} G \bar{d} \sin \theta-C_{d} U^{2} \\
=S_{2} G \bar{d} \sin \theta-C_{D} Q^{2} / \bar{d}^{2} .
\end{gathered}
$$


Fig. 3 A turbulent plume on a slope of $30^{\circ}, B_{0}=0.028$, generated in the same manner as the flow shown in Fig. 1. At the time of this photograph, the broad intrusion of mixed fluid into the environment above the maximum depth of the plume is beginning to form. The clear fluid above the upper part of the downflow indicates that the downflow is entraining environmental fluid. This continues into the overshoot region.

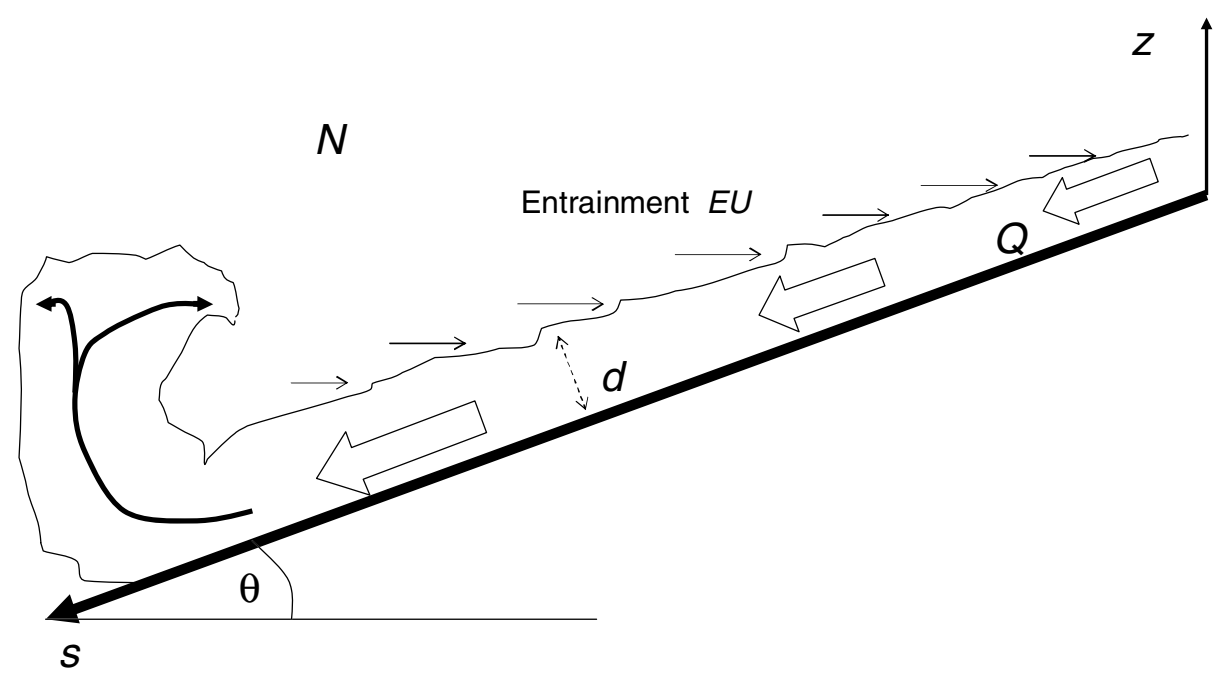

Fig. 4 Schematic depiction of an experimental flow of a plume with significant variables, showing overshoot and spring-back, with $Q=d U$. 


\section{0 / Peter G. Baines}

Here $E$ (without subscript) is the entrainment coefficient, and $S_{2}$ is a constant with values ranging from 0.6 to 0.9 and taken here to be 0.75. Equations (12) and (13) are essentially the same as Eqs (7) and (8). From these, Eq. (14) may be manipulated to give an equation for $\bar{d}$ of the form:

$$
\frac{\mathrm{d} \bar{d}}{\mathrm{~d} s}=2 E+C_{D}-S_{2} \text { Ri } \tan \theta .
$$

$E$ is a function of the Richardson number as defined in Eq. (3), and although several options are possible, the form used here is (Turner, 1986):

$$
\begin{array}{rlrl}
E & =0.08 & \mathrm{Ri}<0, \\
E & =\frac{0.08-0.1 \mathrm{Ri}}{1+5 \mathrm{Ri}}, & & 0<\mathrm{Ri}<0.8, \\
& =0, & & \mathrm{Ri}>0.8 .
\end{array}
$$

In these flows $\mathrm{Ri}$ is generally somewhat less than unity and the entrainment term dominates in Eq. (15), so that $\bar{d}$ increases downslope. This regime was observed for the larger values of $B_{0}$ for slopes of $30^{\circ}, 25^{\circ}$ and $20^{\circ}$ and of course all values at $90^{\circ}$. It was even observed for some values at $12^{\circ}$.

\section{c The double outflow regime (3)}

A third type of flow regime was observed for a narrow range of parameters, namely $30^{\circ}$ slope for small $B_{0}$ only. A photograph of this flow is shown in Fig. 5. These flows initially behaved like plumes, with entrainment occurring throughout the downflow. Subsequently, however, a second region of outflow appeared from the downflow, much higher in the water column and well above the main outflow at the bottom. The fluid supplying this upper outflow appeared to be drawn from fluid rising from the vicinity of the lower outflow region, constituting a rising stream just above the downflow on the slope in the region between them. This rising motion was seen via 'bubbling motion' just above the downflow in this region between the two outflows and is drawn towards the downflow by the entrainment. It would appear that this fluid comes from fluid that is entrained into the downflow but is not fully mixed and is carried down to the main outflow where it separates and then rises due to buoyancy. It is also possible that detrainment is occurring in the upper outflow regime, so that this part of the flow is in the gravity current regime. This surprising and highly unusual flow over this narrow parameter range is not yet fully understood and has not been modelled. Animations depicting the development of all three flow regimes are available on the Journal of Fluid Mechanics web site as supplementary material to Baines (2005).

We next discuss the boundary between these regimes. The double outflow regime (3) is regarded as an oddity or a transition region occupying a small part of parameter space, and we concentrate on the boundary between regimes (1) and (2). This boundary occurs because of the breakdown of the gravity current regime, which occurs as the thickness of the cur- rent becomes small. In the gravity current model, from Eq. (9) it is important that the right-hand side not be negative, as otherwise the current thickness would decrease to zero. Putting these two criteria together, namely taking the right-hand side of Eq. (9) to be zero but with $\bar{d}$ and Ri also zero, one obtains a limiting criterion for the validity of the gravity current model:

$$
T \equiv C_{D}+E_{e}-0.2 B^{0.4} \sin \theta=0 .
$$

$E_{e}$ depends on $\theta$ and $\mathrm{Ri}$, but may be assumed to have a maximum value of about $10^{-3}$ ( $\mathrm{Ri}$ is usually not small for small $\theta$, in Eq. (11)). If $T<0$, the gravity current model is no longer applicable. When this barrier is crossed, the smallness of $\mathrm{Ri}$ and the consequent increase in shear will cause greater instability, turbulence, mixing and entrainment, so that the plume model will become applicable. The experimental points are shown in Fig. 6, where the flow regime has been plotted as functions of $B_{0}$ and $\theta$. Figure 6 a shows the results for a smooth slope. In general, each flow may be classified as being in one regime or the other, and the boundary region between them appears to be quite distinct - mixed or indistinguishable types are rare. Though the drag coefficient in these flows may be a function of the Reynolds number (Lofquist, 1960; Baines, 2001), the experiments with smooth slopes are consistent with the boundary between plumes and gravity currents occurring at $C_{\mathrm{D}}+E_{e}=0.011$. The double outflow regime (3) lies embedded within the plume regime, and these points are indicated in Fig. 6a. It should be noted that, in individual runs in the gravity current regime, the value of $B$ generally increases with distance downslope (Baines, 2001 , 2005), so that the initial value, $B_{0}$, is a minimum. Hence, if the criterion for the breakdown of the gravity current regime is expressed in terms of the local value of $B$, it will lie to the right of the curve shown in Fig. 6a. The results of a single set of runs with a much rougher lower boundary (a rubber doormat with knobs) with a slope $\theta=20^{\circ}$ are shown in Fig. 6b. These were consistent with the boundary at $C_{D}+E_{e}=0.018$, reflecting the larger drag coefficient. The effect of the bottom roughness was to convert plumes into gravity currents over part of the parameter range. Details of this are given in Baines (2005).

These results and parameter values are valid for laboratory flows in which the Reynolds numbers ranged up to approximately 1400. For much larger Reynolds numbers, one may expect some variation in the position of the flow boundaries but that the same relationships and pattern of phenomena will still occur.

\section{Application to oceanic flows}

Real oceanic downslope flows are much more complex than those of the experiments described in Section 2. They are generally three-dimensional and influenced by the Earth's rotation. Eddies and complex flow structures may occur on a plane slope, and downslope currents may be density stratified and sheared in the vertical. In many situations, however, the 
Mixing in Downslope Flows in the Ocean - Plumes versus Gravity Currents / 411

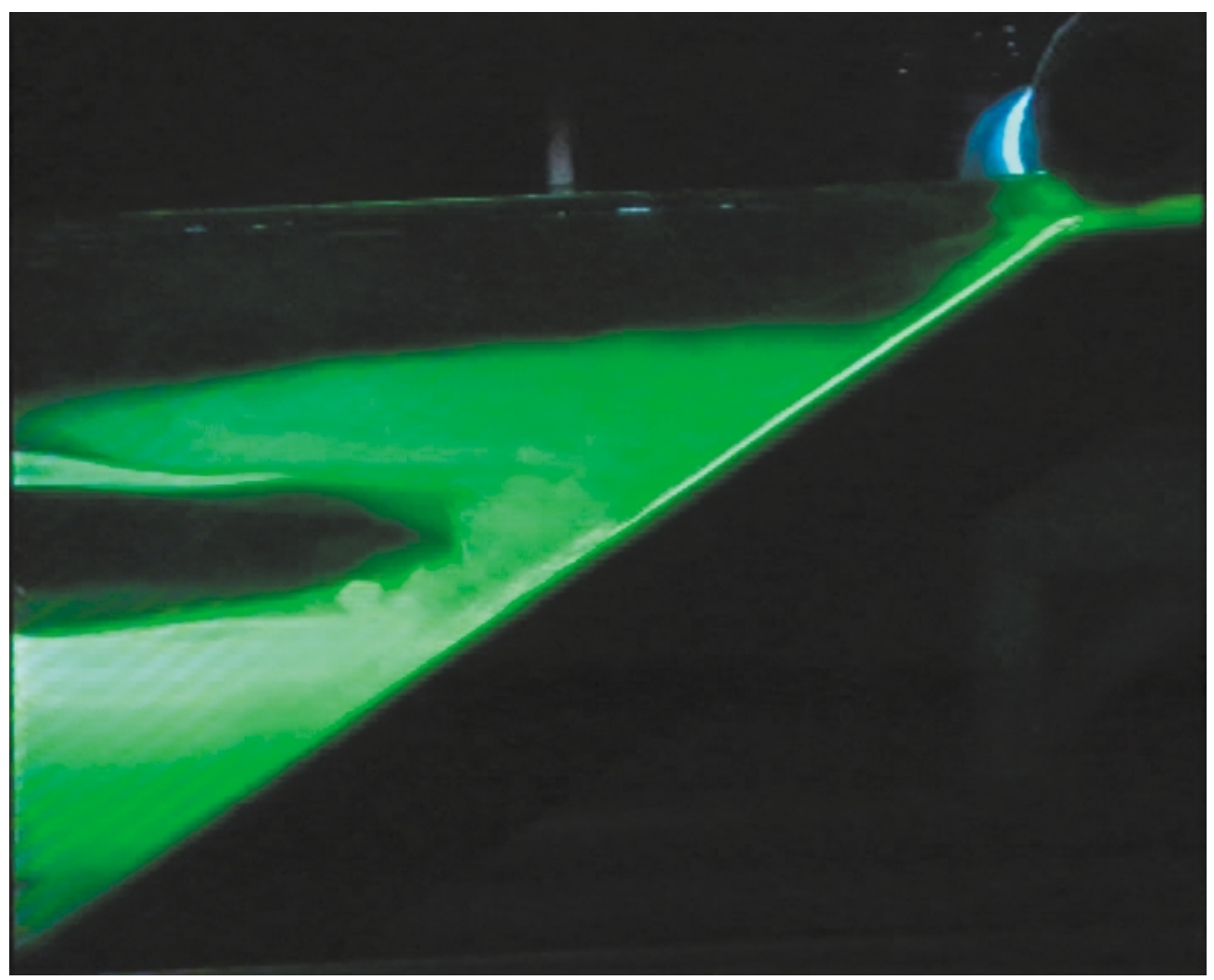

Fig. 5 An example of the double outflow regime on a slope of $30^{\circ}$, with $B_{0}=0.004$. The thickness of the downflow is small, but it is still turbulent and has the character of an entraining plume, which produces the main outflow at the bottom, as for Fig. 3. Here, however, fluid appears to rise from this region above the downflow to a second outflow region above. In crossing the intermediate region, it is drawn toward the downflow by the entrainment, with conspicuous upward bubbling occurring just above it.

shear is concentrated in a thin Ekman layer adjacent to the bottom boundary, and the velocity of the bulk of the fluid in the downflow is locally approximately unidirectional. Further, stratification within the downflow is usually small compared with the density change between the downflow and the environment, and mixing processes associated with entrainment and detrainment adjust on time scales that are much shorter than those of the evolution of mesoscale eddies and geostrophically balanced flows. In these situations the models of the preceding section may be used to estimate the local mixing properties of the flow and whether it is detraining or entraining. If one wishes to model these flows numerically, it indicates which type of parameterization is most appropriate. Here it is important to identify the direction of the mean flow velocity, which may be assumed to be in an approximately geostrophically balanced state. This determines the relevant velocity, the path and the effective slope angle. The dynamical equations in the vertical plane of fluid motion are then essentially the same as the previous section, since the Coriolis force acts normal to it. The above experimental results may then be applied to this geostrophically balanced vertical 'slice', and applications to oceanic flows below are made on this basis. If the dense downflow is confined to a channel, or canyon, then these assumptions are more obviously applicable. The bottom drag provides additional com- plications. Whereas this drag may be regarded as frictional in the experiments, in the ocean there may well be a combination of frictional and form drag, where the latter is due to topographic variations. The presence of small-scale topographic features may well cause the drag (and drag coefficient) to be much larger than that due to friction alone.

We now proceed to apply the results of the preceding section to a number of particular oceanic flows for which sufficiently detailed observations exist. All of these flows have been the subject of considerable study, but the information gained from the experiments described in Section 2 enables a new perspective in understanding them.

\section{a The Red Sea Outflow}

The first example is the outflow from the Red Sea into the Gulf of Aden. This is a year-round occurrence and consists of dense saline water driven by evaporation in the Red Sea. Here the flow is mostly confined to two channels, the Northern Channel and the Southern Channel, as shown in Fig. 7. Observations of the velocity, temperature and salinity of the flow in these channels were taken as part of the 2001 Red Sea Outflow Experiment (REDSOX), and these have been described by Peters et al. (2005), Peters and Johns (2005, 2006) and Matt and Johns (2007). The REDSOX observations were made during two cruises, February-March 


\section{2 / Peter G. Baines}

(a)

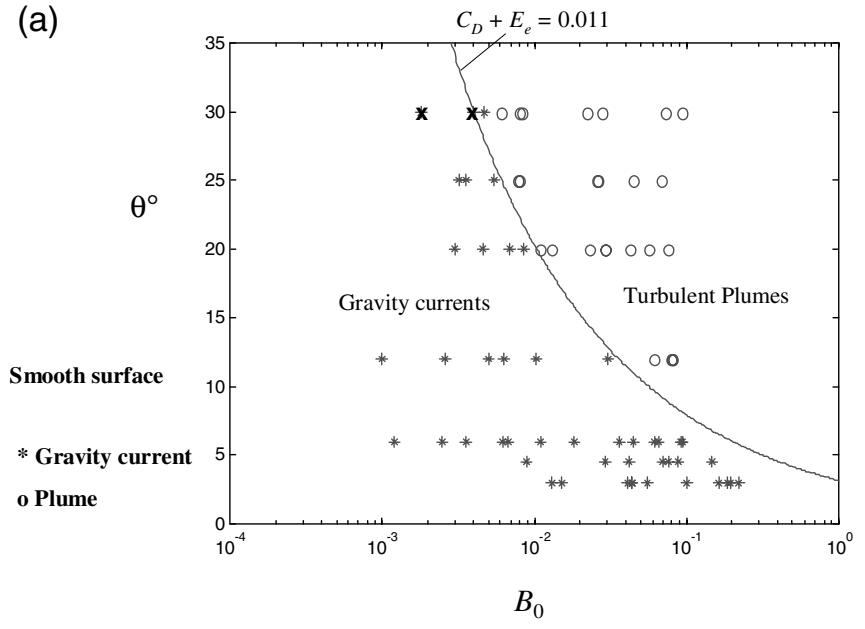

(b)

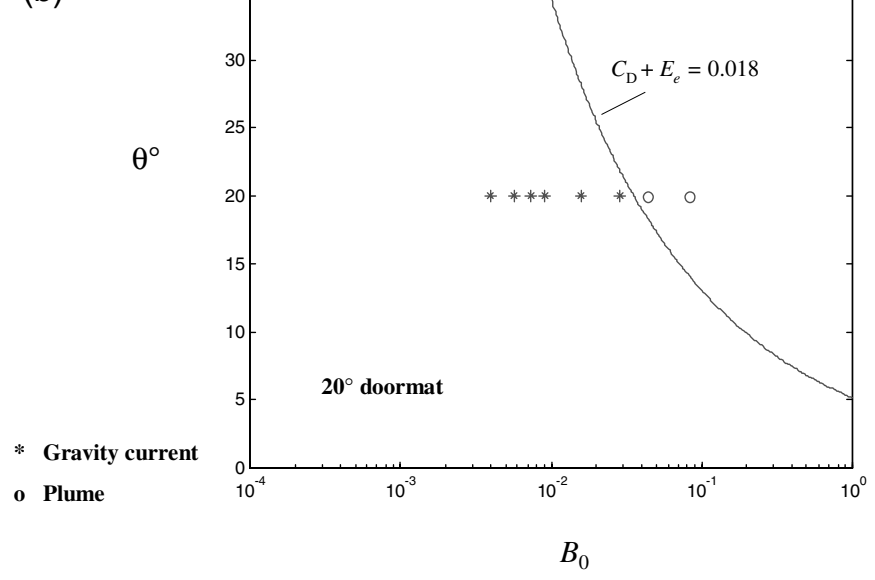

Fig. 6. (a) Points representing experimental runs classified as gravity currents (asterisks) and plumes (circles) for smooth slopes, as functions of slope angle, $\theta$, and parameter $B_{0}$ for each run. The plotted curve is for a constant value of $0.2 B_{0}{ }^{0.4} \sin \theta$, which from Eq. (17) would correspond to a value of $C_{D}+E_{e}=0.011$. The two double outflow runs at $30^{\circ}$ slope are denoted by large asterisks. (b) As for (a), but for rough (doormat) runs at $20^{\circ}$ slope. The boundary value of $0.2 B_{0}{ }^{0.4} \sin \theta$ here is 0.018 , reflecting the larger drag coefficient of the doormat-surface. In general, in any experimental run the value of $B$ increases above the initial value, $B_{0}$, as the fluid moves down the slope, so that the boundary between gravity currents and plumes in terms of local variables is to the right of that shown in these figures.

(winter) and August-September (summer), with outflows being stronger in the winter. This gives four different flow situations (two channels, two seasons), and we examine the state of each. In all situations, the flow of the bottom current is in approximate geostrophic balance and is confined by the channel geometry, but the upper environmental fluid is not.

For both channels the mean bottom slope is small, with a slope angle of approximately $0.2^{\circ}$ (Fig. 2 of Peters et al. (2005)), the channels being essentially embedded in the continental shelf. For the Northern Channel this is approximately uniform over a distance of $130 \mathrm{~km}$, reaching a depth of $700 \mathrm{~m}$; for the Southern Channel it is more variable and over a shorter distance of approximately $90 \mathrm{~km}$, where it reaches a depth of $500 \mathrm{~m}$; these regions are denoted here as the upper Northern and Southern channels. Beyond these end points the slope is much steeper, with mean slope angles of $2.7^{\circ}$ (Northern Channel) and 6.2 (Southern Channel). The fluid in both bottom currents is essentially the same and is marked by its salinity. The overlying water has approximately uniform salinity (apart from the fluid mixed in from the downflow) and is stratified by temperature, with a mean buoyancy frequency, $N$, of $0.007 \mathrm{~s}^{-1}$. For both seasons in both upper channels, the bottom drag is an order of magnitude larger than the interfacial drag on the upper boundary, and the observed values of the drag coefficients are $C_{\mathrm{D}}=0.0093$ (Northern Channel) and 0.0021 (Southern Channel). Values of $Q, \bar{d}$ and $G$, and corresponding values of $B$ are given in Table 1, which also gives computed values of $0.2 B^{0.4} \sin \theta$. It is clear from these values that $C_{\mathrm{D}}+E_{e}$ is significantly greater than $0.2 B^{0.4} \sin \theta$, and hence, from the analysis of the preceding section, the flows in the upper Northern and Southern channels should be classified as detraining gravity currents for both winter and summer.

Figures 8 and 9, taken from Peters et al. (2005), show plots of the mean velocity and salinity for all four situations. These plots are consistent with the interpretation of the data, that these flows have the structure of detraining gravity currents. If we focus on the flow in the Northern Channel in winter, the (lower) velocity panel shows that the downflow velocity is confined to a region of approximately $100 \mathrm{~m}$ in height with a velocity of order $1 \mathrm{~m} \mathrm{~s}^{-1}$, and that these variables are approximately uniform along the channel in the upper part of the slope, to a distance of approximately $120 \mathrm{~km}$. The salinity field (shown in the upper panel) is also approximately uniform with position along the downflow, but there is evidence of considerable mixing into the fluid above. Further, this overlying fluid is clearly not part of the downflow, as it is effectively stationary when compared with the downflow velocities. The mixing of saline water into the overlying fluid will tend to make it slightly more dense causing it to move to a slightly deeper environment, but as with the laboratory experiments (Baines, 2001), isolated mixing events occurring just above the downflow will cause interleaving and turbulence on the same scale (Peters and Johns, 2005). At depths greater than $700 \mathrm{~m}$, where the bottom slope becomes much steeper, the flow approaches the boundary for the changeover to the plume regime, but Fig. 8 suggests that it may also be reaching its neutral density level. Examination of the other flows - Northern Channel in summer, and the Southern Channel in winter and summer - shows that the same conclusions apply to the flows in the upper channel: all of them may be classified as gravity currents as defined in the preceding section, based on laboratory experiments.

Further comparisons such as quantitative estimates of the entrainment are probably unrealistic with this data set. The volume of the detrained fluid above the downflow depends on the motion of the overlying fluid and its response to the injection of detrained dense fluid. The flows depicted in Figs 8 and 9 consist of a 'snapshot' taken over three or four weeks and time histories of the properties of the overlying fluid are not available for any of these cases. 


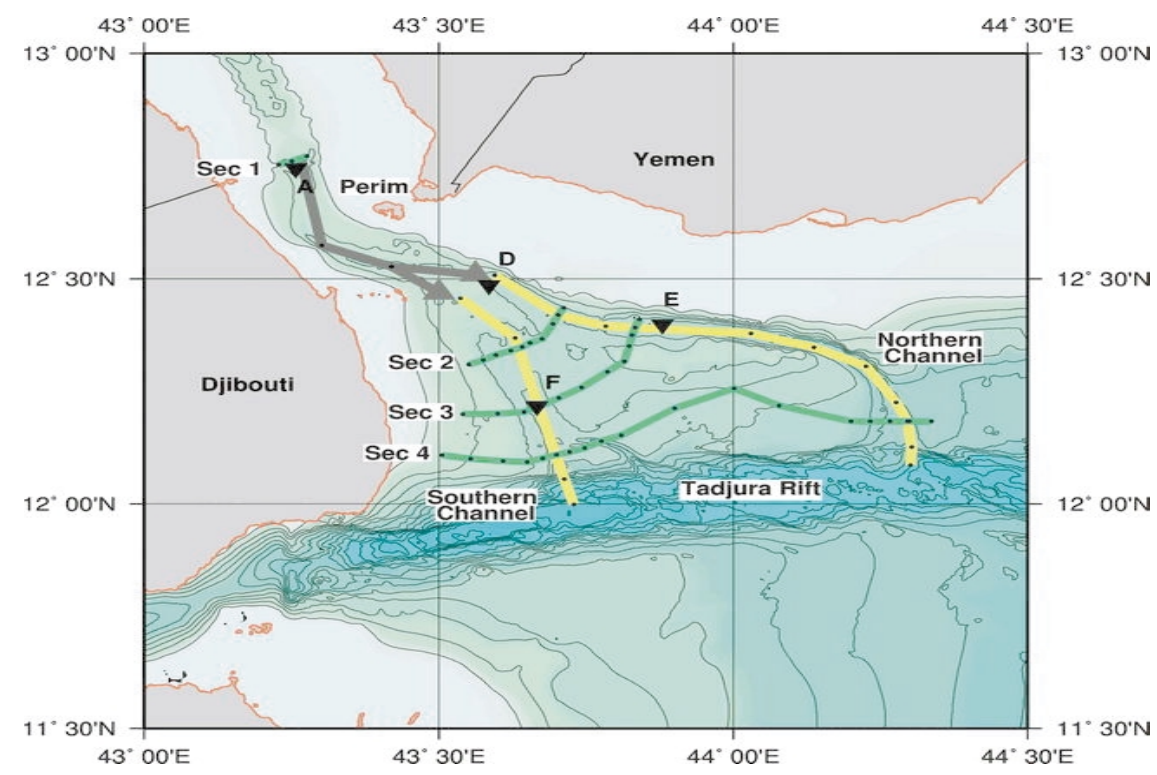

Fig. 7 The western Gulf of Aden showing the entrance region to the Red Sea. The two principal channels (Northern and Southern) for dense outflow are also shown. Depth contours are at $100 \mathrm{~m}$ intervals. Sections 1-4 were occupied during the REDSOX-I and -II surveys in 2001 and dots denote ConductivityTemperature-Depth/Lowered Acoustic Doppler Current Profiler (CTD/LADCP) stations (reproduced from Matt and Johns (2007) by permission of the American Meteorological Society).

TABLE 1. Parameter values for various oceanic downslope flows as described in Section 4. The final column shows the flow regime inferred from the given parameter values, according to Eq. (17). Drag coefficients with question marks are nominal values.

\begin{tabular}{|c|c|c|c|c|c|c|c|c|c|}
\hline Location & $C_{D}$ & $\begin{array}{l}\bar{d} \\
\mathrm{~m}\end{array}$ & $\underset{\mathrm{m}^{2} \mathrm{~s}^{-1}}{Q}$ & $\begin{array}{c}g^{\prime} \\
\mathrm{m} \mathrm{s}^{-2}\end{array}$ & $\begin{array}{c}N \\
\mathrm{~s}^{-1}\end{array}$ & $B$ & $\begin{array}{l}\theta \\
\operatorname{deg}\end{array}$ & $0.2 B^{0.4} \sin \theta$ & \\
\hline \multicolumn{10}{|l|}{ Red Sea } \\
\hline winter N Channel & 0.0093 & 100 & 120 & 0.026 & 0.007 & 0.064 & $0.195^{\circ}$ & $2.27 \times 10^{-4}$ & G Current \\
\hline winter S Channel & 0.0021 & 100 & 50 & 0.026 & 0.007 & 0.0265 & $0.195^{\circ}$ & $2.17 \times 10^{-5}$ & G Current \\
\hline summer S Channel & 0.0021 & 50 & 5 & 0.033 & 0.007 & 0.0049 & $0.195^{\circ}$ & $8.11 \times 10^{-5}$ & G Current \\
\hline \multicolumn{10}{|l|}{$\begin{array}{l}\text { Denmark Strait } \\
\text { overflow }\end{array}$} \\
\hline Upper slope & 0.0029 & 100 & 100 & 0.0008 & 0.0014 & 0.43 & $0.25^{\circ}$ & 0.0006 & G Current \\
\hline \multicolumn{10}{|l|}{ Section t1d - distance } \\
\hline $20 \mathrm{~km}$ from sill & 0.00082 & 271 & 184 & 0.00096 & 0.0014 & 0.55 & $0.82^{\circ}$ & 0.00225 & Plume \\
\hline - distance $30 \mathrm{~km}$ from sill & 0.0036 & 197 & 95 & 0.0006 & 0.0014 & 0.72 & $0.82^{\circ}$ & 0.0025 & G Current \\
\hline \multicolumn{10}{|l|}{ Black Sea inflow } \\
\hline - shelf & $0.0015 ?$ & 7 & 5.6 & 0.04 & 0.012 & 0.0064 & $0.175^{\circ}$ & $3.3 \times 10^{-5}$ & G Current \\
\hline \multicolumn{10}{|l|}{$\begin{array}{l}\text { Mediterranean Atlantic } \\
\text { outflow }\end{array}$} \\
\hline Camarinal Sill & $0.0015 ?$ & 100 & 100 & 0.014 & 0.0021 & 0.005 & $8.5^{\circ}$ & 0.0036 & Plume \\
\hline - distance $100 \mathrm{~km}$ from sill & $0.0015 ?$ & 100 & 100 & 0.004 & 0.0021 & 0.06 & $0.4^{\circ}$ & 0.0004 & G Current \\
\hline
\end{tabular}

\section{b The Antarctic Ross Sea Overflow}

In the Ross and Weddell seas of Antarctica, dense fluid overflows the continental shelf and flows down the continental slope at the western ends. For each of these seas, this occurs over an extensive range of locations, with a variety of condi- tions. Recent observations as part of the AnSlope programme in 2003 and 2004 have enabled a detailed description of the pattern of flow in the western Ross Sea, where these downflows are particularly intense. The data set is quite extensive, and only the part with the strongest outflow is considered 
414 / Peter G. Baines

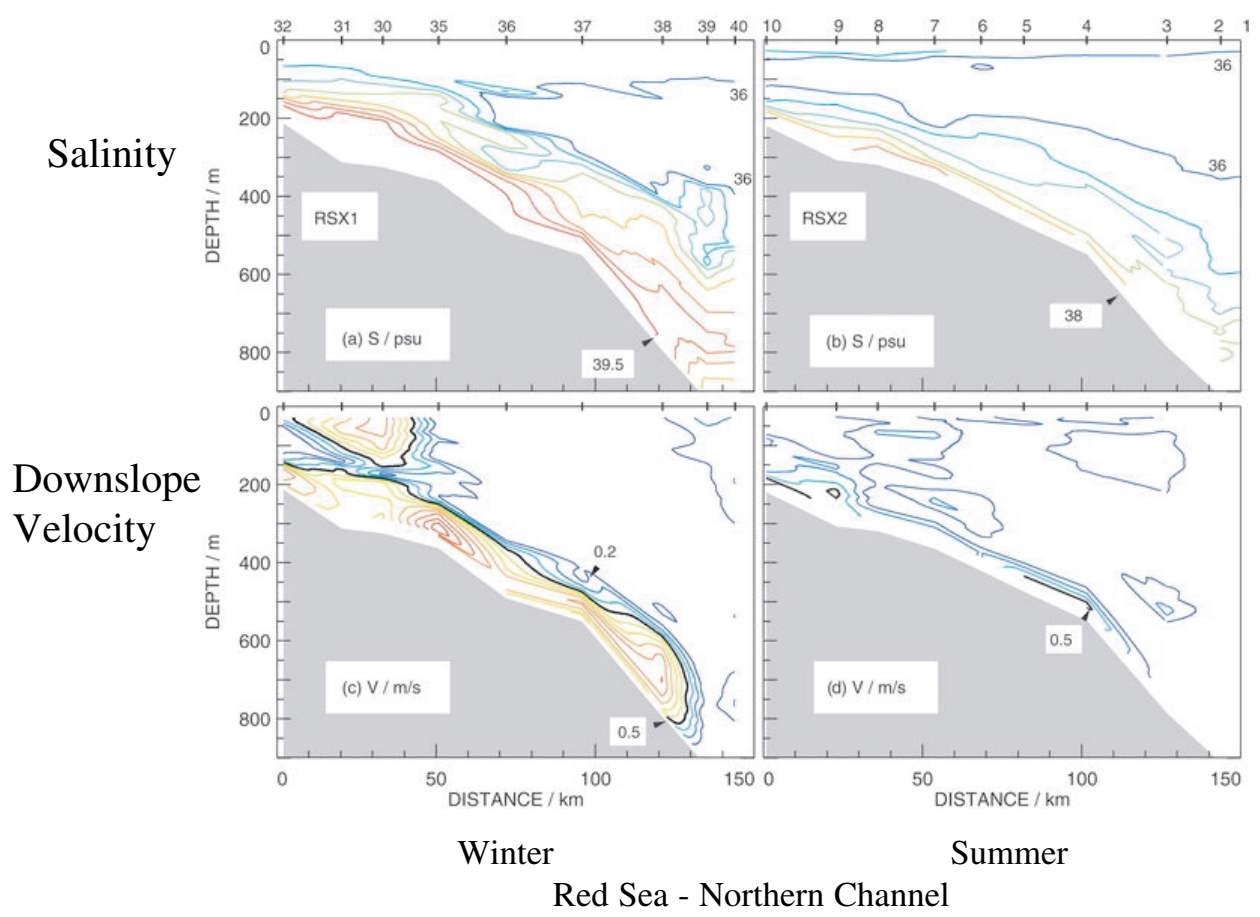

Fig. 8 Sections showing properties of the Red Sea outflow from Bab el Mandeb Strait along the Northern Channel. Left- (right-) hand panels show results for the winter REDSOX-I (summer REDSOX-II) season. Upper (lower) panels show salinity (downslope velocity) with contour interval 0.5 psu $\left(0.1 \mathrm{~m} \mathrm{~s}^{-1}\right)$. Numbers at the top denote CTD/LADCP cast numbers (reproduced from Peters et al. (2005) by permission of the American Meteorological Society).

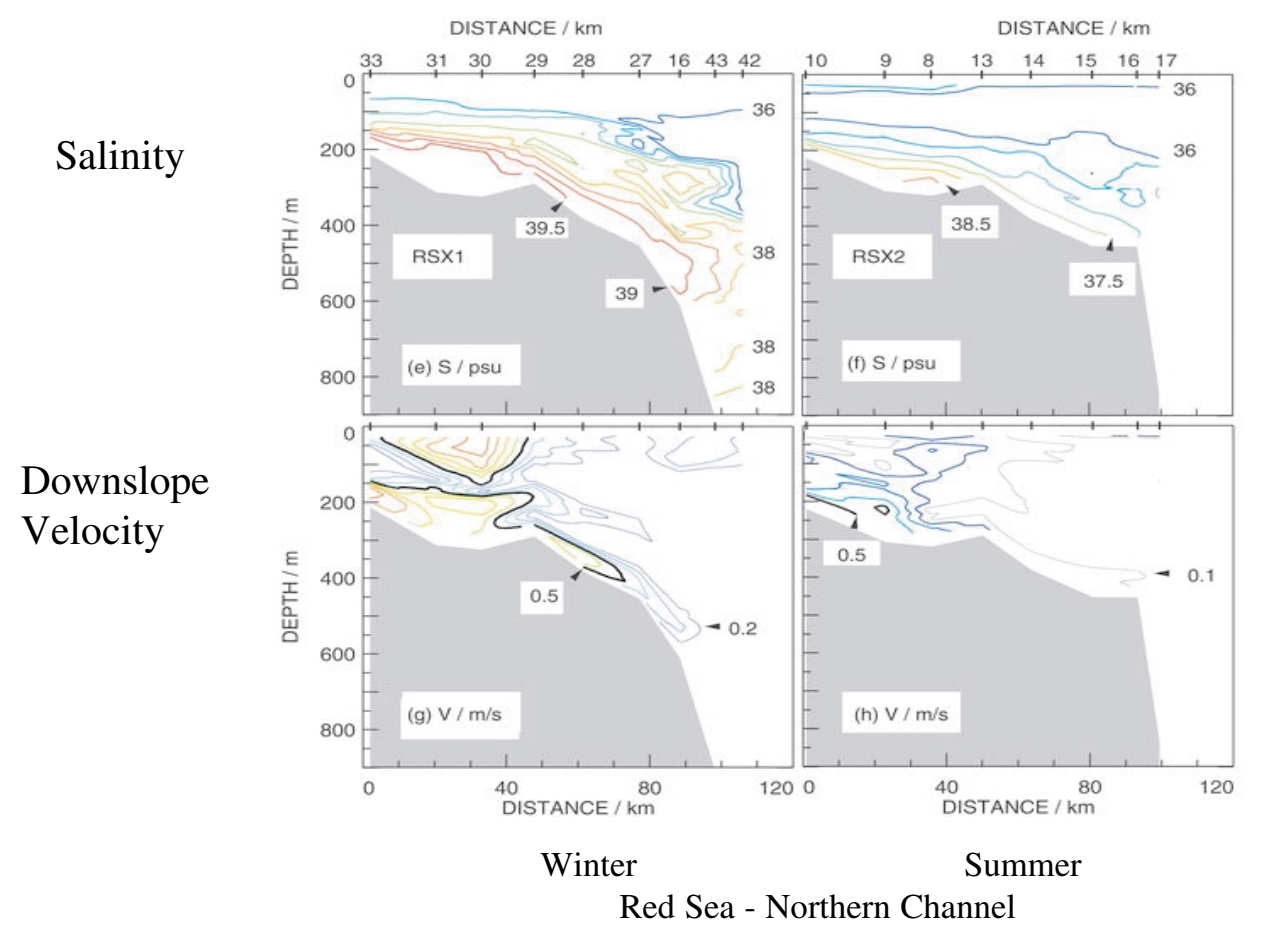

Fig. 9 As for Fig. 8, but for the Southern Channel (reproduced from Peters et al. (2005) by permission of the American Meteorological Society).

here. The location and approximate path are depicted in Fig. 10. Data used were obtained from Gordon et al. (2004) and from A. Gordon (personal communication, 2007). Dense flows on continental slopes that are not channelled in a canyon (for example) descend at an effective slope angle that is somewhat smaller than that of the steepest slope. Following 


\section{Mixing in Downslope Flows in the Ocean - Plumes versus Gravity Currents / 415}

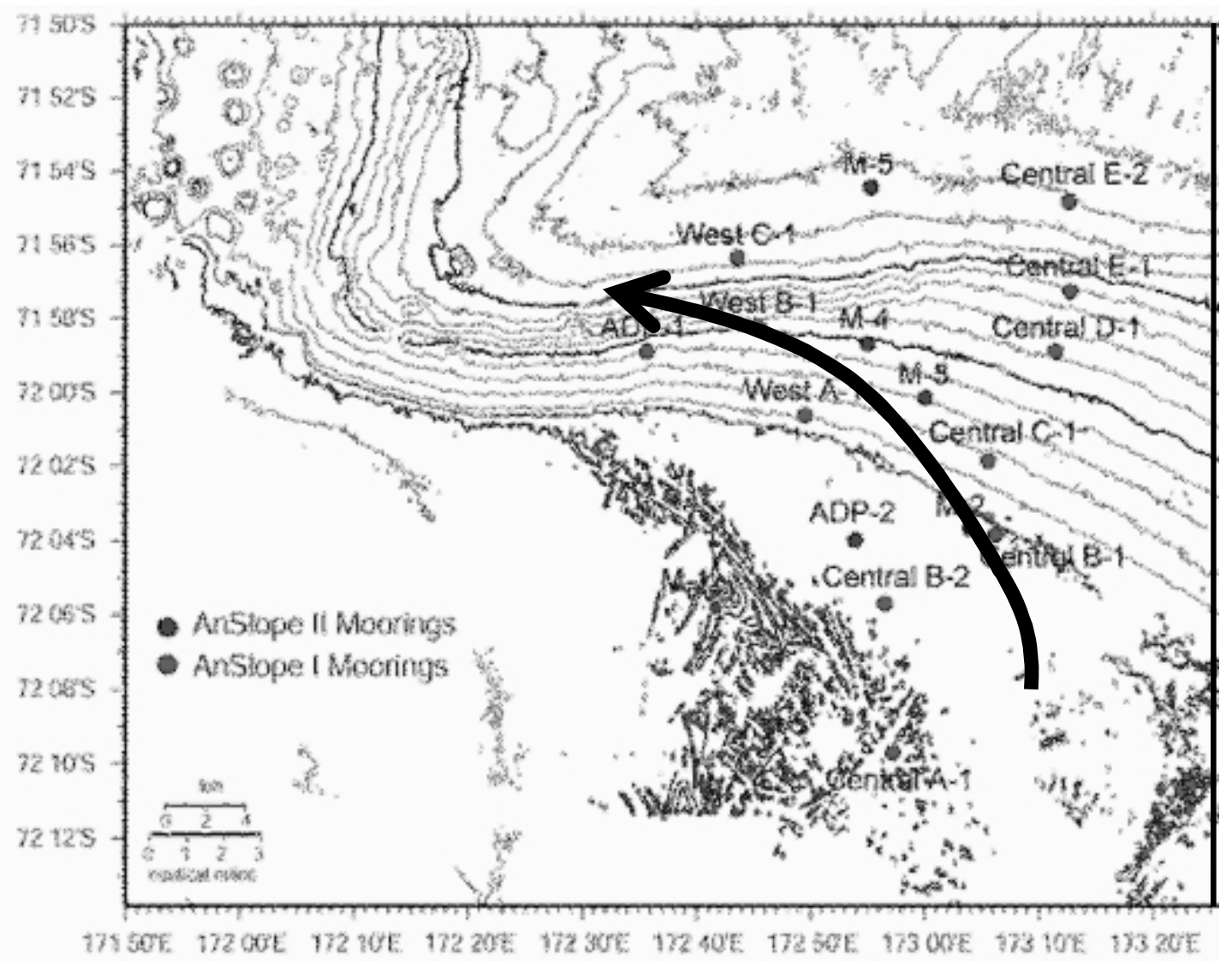

Fig. 10 Topography of the continental slope of the western part of the Ross Sea, Antarctica, showing the central path (solid curved arrow) of the main outflow of dense water. Depth contours are at $100 \mathrm{~m}$ intervals. Some mooring locations for the Anslope experiment (Gordon et al., 2004) are shown (figure courtesy of A. Gordon).

the path of the strongest velocity, the dense fluid here descends the slope at an effective slope angle of $7^{\circ}$ (where the maximum slope is $\left.10^{\circ}\right)$, with a measured drag coefficient of 0.0025. Assuming a Froude number $\left(F=U /\left(g^{\prime} \bar{d}\right)^{1 / 2}\right)$ of approximately one at the top of the slope, with $Q=90 \mathrm{~m}^{2} \mathrm{~s}^{-1}$, $\bar{d}=200 \mathrm{~m}$, we obtain $g^{\prime}=0.001$, and $0.2 B^{0.4} \sin \theta=0.0093$. With $E_{e}$ having a maximum value of 0.001 , it is clear that the condition for gravity currents is violated, and this flow is expected to have the character of an entraining plume, as shown in Table 1. This is consistent with overall observations of this downflow, since the volume flux in this plume is observed to increase by more than a factor of two by the time it reaches depths of $2000 \mathrm{~m}$. These flows are complex and time dependent, with tides having a significant effect on the supply of dense fluid to the slope, but these mean conditions are sufficient to show that the appropriate model on the slope is that of plume dynamics and that this should also extend to other locations in the vicinity.

\section{c The Denmark Strait Overflow}

The Denmark Strait overflow consists of a broad region of dense fluid that flows over the sill between Greenland and Iceland, which has a maximum depth of $600 \mathrm{~m}$. It then descends along the Greenland continental slope into the
Atlantic in an approximate state of balance between buoyancy, Coriolis force and bottom friction. Here, representative values of the five parameters required for the model of Section 2 are calculated for the upper part of the downflow downstream of the sill and for locations across a section in the lower part, at a distance of $200 \mathrm{~km}$ from the sill. Data used were collected in 1997 and 1998 and obtained from Girton and Sanford (2003) and Käse, Girton and Sanford (2003).

After passing over the sill, the effective bottom slope along the path of the overflow is quite small, and in consequence the flow is expected to have the mixing properties of a detraining gravity current, with detrainment increasing with bottom slope. For instance, at a distance of $60 \mathrm{~km}$ downstream of the sill, with an effective slope of $0.25^{\circ}, \bar{d}=100 \mathrm{~m}, U=1 \mathrm{~m} \mathrm{~s}^{-1}$ and a background $N=1.4 \times 10^{-3}$, the value of $0.2 B^{0.4} \sin \theta$ is much less than a representative drag coefficient of more than $10^{-3}$ (see Table 1 ). With such small slopes, this seems likely to apply up to the region where the slope steepens, beyond a distance of $125 \mathrm{~km}$ from the sill.

At greater distances from the sill where the slope becomes steeper, values have been calculated across section t1d near $31^{\circ} \mathrm{W}$ of velocity and density data taken in September 1998. The location and details of this section are shown in Fig. 11, which shows the depth, density, velocity and along-flow 

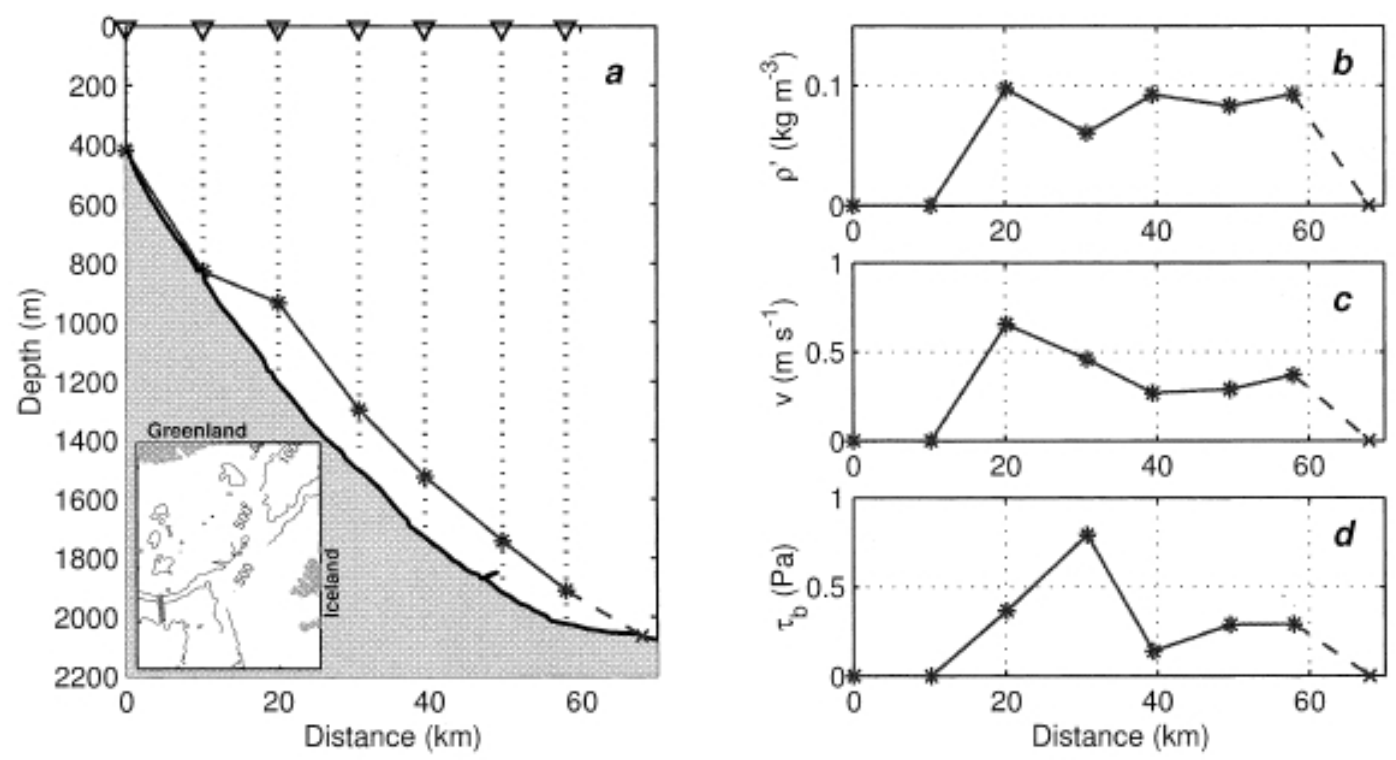

Fig. 11 (a) Topography of the Denmark Strait (shown in inset) between Greenland and Iceland, and the location of section t1d (marked by the dark line) where data were taken by Girton and Sanford in September 1998, and the depth of the dense overflow, identified by the 27.8 isopyenal, at this section. Panels (b), (c) and (d) show the mean overflow density anomaly; the mean overflow velocity, and the observed value of the bottom stress, perpendicular to the section (reproduced from Girton and Sanford (2003) by permission of the American Meteorological Society).

bottom stress at five locations across the section. These data are used to calculate the five parameters for each location, and the details are given in Table 1 . At the $20 \mathrm{~km}$ location, where the downflow is strongest and thickest, the flow satisfies the criterion for a plume. At the four others it does not, and at these locations it is classified as a gravity current. Taken at face value, these simple numbers imply that the strongest portion of the overflow at this section has the character of an entraining plume. This may be assumed to be a region of approximately $20 \mathrm{~km}$ across and is a substantial portion of the total current. Flow at the remaining locations is a detraining gravity current, by these criteria. It should be noted that these observations are 'spot' values, and there is considerable variability in, for example, the bottom stress, which affects these results. However, it would appear that the inference that the flow is part entraining plume and part detraining gravity current at this section is probably valid.

\section{d Mediterranean Outflow to the Black Sea, or Black Sea Inflow}

Evaporation over the Mediterranean Sea causes its surface waters to be denser than those of the Black Sea, and this drives an exchange flow through the straits of the Dardanelles and Bosphorus (Gregg and Özsoy, 2002). Mixing occurs in the Bosphorus, particularly on the northern side of two prominent sills in the channel, but this is a different flow regime from that considered here. Dense saline water enters the continental shelf of the Black Sea via a channel from the Bosphorus, which confines it for at least part of the way across the continental slope, which has an overall width of about 30 km (Özsoy et al., 1993; Gregg and Özsoy, 1999). Here the ambient environment is stratified, and the laboratory experiments may be invoked to infer the mixing character of the flow. Using data from Gregg and Özsoy (1999), the dense current has a speed of approximately $0.8 \mathrm{~m} \mathrm{~s}^{-1}$ and a thickness of about $7 \mathrm{~m}$, on a slope of about $1.25 \times 10^{-3}$. Other parameters and $B$-values are given in Table 1, with a nominal drag coefficient of 0.0015 . Although the drag coefficient is unknown, realistic values for the ocean imply that the flow has the character of a detraining gravity current on the continental shelf. On reaching the continental slope, however, the slope becomes much steeper, reaching values up to 0.175 (an angle of $10^{\circ}$ ) at depths of about $400 \mathrm{~m}$. With such a steep slope, though detailed data are lacking, it seems likely that the dense fluid will descend at an effective slope close to this angle and that the flow will move into the plume regime, unless the bottom surface is much rougher than average.

\section{e The Mediterranean Outflow to the Atlantic}

The Mediterranean outflow differs from the other examples in that the bottom topography of the region is complex and contains topographic features that do not appear to be fully resolved in available data sets. A plot of topography near the sill is shown in Fig. 12 (taken from Brandt et al. (1996)), which indicates the variability. Dense fluid from the Mediterranean outflow exits the Strait and passes over the Camarinal Sill, which has a depth of between 250 and $300 \mathrm{~m}$ on each side of a central minimum where the depth is less than $200 \mathrm{~m}$. This fluid then undergoes substantial mixing and entrainment as it descends further to a depth of approximately $600 \mathrm{~m}$ (Price et al., 1993; Price and Baringer, 1994), which increases the total volume transport by a factor of 2.5. Beyond this depth, mixing and entrainment are minimal. Smoothed topography does not provide sufficient information to 


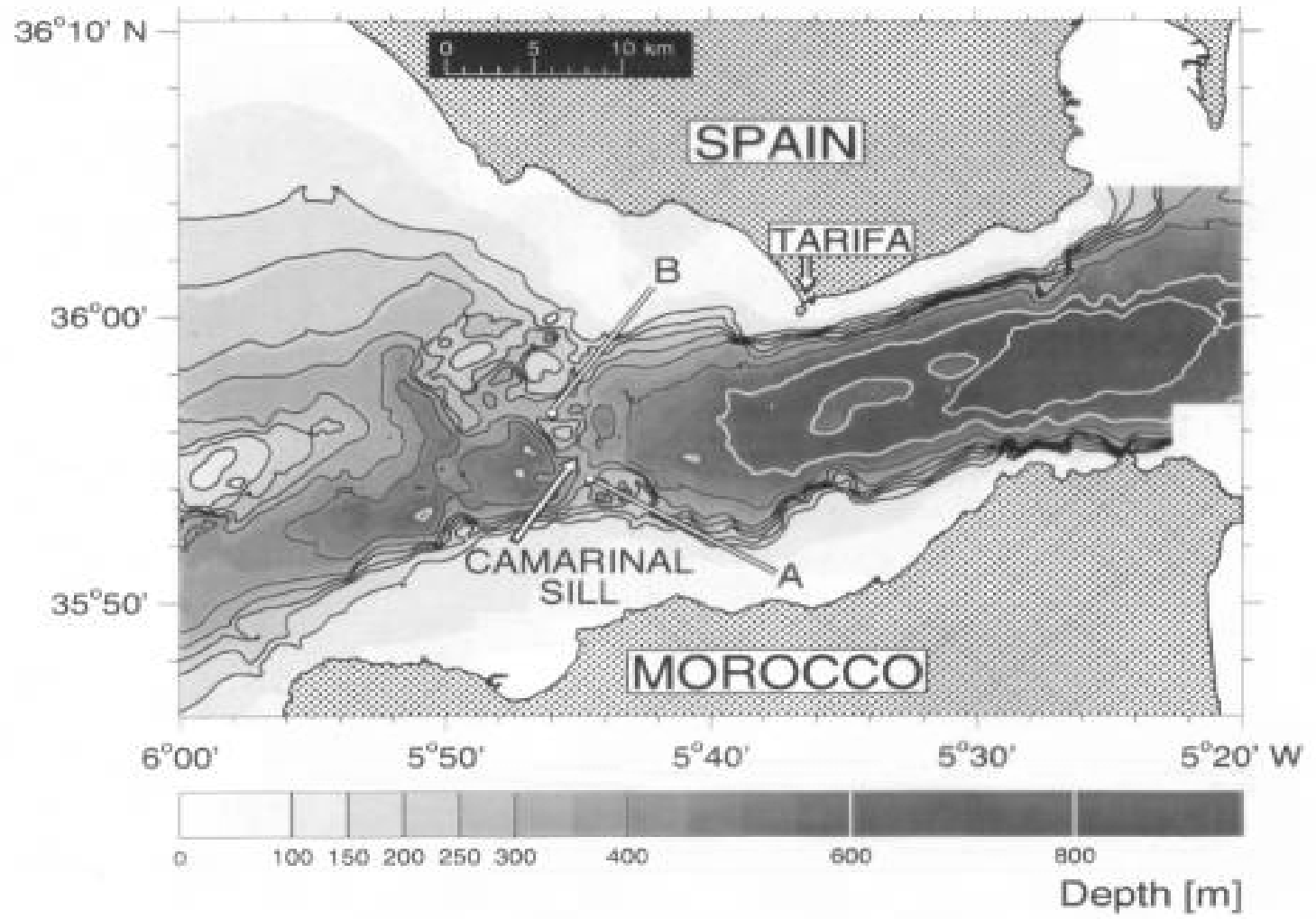

Fig. 12 Topography of the Straits of Gibraltar and the region immediately to the west, including the Camarinal Sill, showing the variability and steepness of the topography in the region. Regions A and B denote the deeper parts of the sill (reproduced from Brandt et al. (1996) by permission of the American Geophysical Union).

understand this mixing behaviour. Some representative numbers for two regions along this path are given here. The first is the lee side of the Camarinal Sill, and the second is a region near $100 \mathrm{~km}$ from the sill at a depth of approximately $700 \mathrm{~m}$ where the smoothed topographic slope is small.

The Camarinal Sill is very steep, with a lee slope of 0.15 extending over a horizontal distance of about $2 \mathrm{~km}$ (from Fig. 12). Using data from Price and Baringer (1994) for the parameters $Q, N$ and $g^{\prime}$, one obtains the values given in Table 1, which indicate that the flow down the lee slope has the character of an entraining plume. If the value of the Richardson number on this slope is close to zero, entrainment in this region could double the transport. More detailed observations of the dense downflow over the Camarinal Sill by Wesson and Gregg (1994) that include the variation with the tidal cycle are consistent with these inferences. Though the flood phase (eastward motion) of the tide suppressed the dense downflow completely, the ebb phase had larger $Q$ values than the value $100 \mathrm{~m}^{2} \mathrm{~s}^{-1}$ given in Table 1 and hence plume flow is expected on the western slope.

At a deeper level, between sections D and E of Price et al. (1993), the mean bottom slope has the value 0.0067; the effective slope will be less than this (due to rotation), but taking this value and again using flow parameters from Price and Baringer, one obtains values given in Table 1 that give a detraining gravity current in this range.
These two examples along the Mediterranean outflow track serve to show that the mixing properties of the downflow are sensitive to the nature of the bottom slope - taking mean values over distances of $20 \mathrm{~km}$ or more will give a detraining gravity current over the entire range, which is obviously not correct. If instead the flow descends in a sequence of short regions that are sufficiently steep to give plume dynamics, the mixing will be much stronger, the entrained volume larger and the overall penetration depth of the downflow will be much less. This is apparently what happens in the upper $600 \mathrm{~m}$ of the Mediterranean outflow.

\section{Conclusions}

As demonstrated in the laboratory, downslope flows into nonrotating density-stratified environments at sufficiently large Reynolds numbers are mostly of two types: detraining gravity currents on sufficiently small slopes and entraining plumes on sufficiently steep slopes. Gravity currents have relatively sharp, distinct upper boundaries; the downward buoyancy force is largely balanced by the bottom drag; they form intrusions into the environment when they reach their neutral level; and they mostly detrain fluid but entrain a small amount as well. For plumes on the other hand the downward buoyancy force is balanced by the entrainment of environmental fluid into the bottom current due to Kelvin-Helmholtz billows 


\section{8 / Peter G. Baines}

over most of their length; the downflow overshoots its equilibrium level and then springs back to spread as an intrusion over a broad range of heights; entrainment occurs down into the overshoot region, and some fluid may be recirculated into the downflow after spring-back.

In any given situation, the flow type depends primarily on the drag coefficient $C_{D}$, the bottom slope $\theta$ and the buoyancy number, $B$. The condition for gravity currents is, from Eq. (17):

$$
C_{D}+E_{e}>0.2 B^{0.4} \sin \theta
$$

$C_{D}$ really represents the drag coefficient for the bottom and the overlying fluid, where the latter is much smaller (typically $10 \%)$. The entrainment coefficient for gravity currents is also small (of order $10^{-3}$ ) and depends on the Richardson number, so that the bottom drag dominates the left-hand side. In these gravity currents, the total drag plus the entrainment is sufficient to balance the buoyancy force acting on the downflow. If Eq. (18) is not satisfied, the mixing dynamics are quite different, and the flow has the character of plumes, in which the downward buoyancy force is balanced by much larger entrainment of environmental fluid into the downflow.

At least one other type of flow regime is observed, namely the double-outflow regime observed on $30^{\circ}$ slopes for small values of $B_{0}$. This is not well understood. The flow has the basic character of an entraining plume, but it seems to involve fluid that is entrained into the downflow at upper levels of the slope but is not fully mixed into it. This fluid then leaves the main downflow at the bottom and rises outside (above) it to levels higher in the water column, where it spreads and forms a separate outflow region, isolated from the lower one.

Downslope flows in the ocean are much more complex than these two-dimensional (in the mean) flows in the laboratory, but these results may still be applied because the mixing qualities depend on local values of the parameters and involve much shorter time scales than those of the main structure of the flow. What is required in order to apply them is that the downflow be approximately unidirectional in the mean, with density variation concentrated near its upper boundary, and the flow be in approximate dynamical (geostrophic) balance across the flow. The equations governing the flow in the direction of motion are then essentially those of the twodimensional experiments, and the models of Section 2 may be applied for the purposes of determining the mixing properties if the parameter values are taken along the direction of flow. This may occur on broad slopes where the conditions along the slope vary on a sufficiently long length scale or in channels where the flow is topographically steered.

These experiments have been applied to a variety of locations in the ocean, where the flow approximately satisfies these criteria. These include the channelled outflow from the Red Sea, the inflow into the Black Sea, the Denmark Strait overflow, the flow over the Antarctic continental slope from the western Ross Sea and the Mediterranean outflow into the Atlantic Ocean. Although the condition for gravity currents or plumes depends on the bottom drag coefficient $C_{D}$ and the buoyancy number $B$, the factor that shows the greatest variability and principally determines the flow character is the effective bottom slope, $\theta$. Flows on gently sloping continental shelves are all gravity currents by this criterion, and the path on continental slopes needs to be sufficiently steep to produce entraining plumes. A broad flow may have the character of a plume in one part of a transverse section and that of a gravity current in another. The region with the most complex bottom topography is that of the Mediterranean outflow, where it appears that the central part of the flow may change from a gravity current to a plume and back again in several locations along the flow path.

\section{References}

BAINES, P.G. 1995. Topographic Effects in Stratified Flows. Cambridge University Press, 482 pp.

BAINES, P.G. 1999. Downslope flows into stratified environments - structure and detrainment. In: Mixing and Dispersion in Stably Stratified Flows, Proc. $5^{\text {th }}$ IMA Conf. on Stratified Flows, P. Davies (Ed.), Clarendon Press, Oxford. pp. 1-21.

BAINES, P.G. 2001. Mixing in flows down gentle slopes into stratified environments. J. Fluid Mech. 443: 237-270.

BAINES, P.G. 2002. Two-dimensional plumes in stratified environments. $J$. Fluid Mech. 471: 315-337.

BAINES, P.G. 2005. Mixing regimes for the flow of dense fluid down slopes into stratified environments. J. Fluid Mech. 538: 245-267.

BRANDT, P.; W. ALPERS and J.O. BACKHAUS. 1996. Studies of the generation and propagation of internal waves in the Strait of Gibraltar using a numerical model and synthetic aperture radar images of the ERS1 satellite. $J$. Geophys. Res. 101: 14237-14252.

BRITTER, R.E. and P.F. LINDEN. 1980. The motion of the front of a gravity current travelling down an incline. J. Fluid Mech. 99: 532-543.

ELLISON, T.H. and J.S. TURNER. 1959. Turbulent entrainment in stratified flows. J.Fluid Mech. 6: 423-448.
FERNANDO, H.J.S. 1991. Turbulent mixing in stratified fluids. Ann. Rev. Fluid Mech. 23: 455-493.

GIRTON, J.B. and T.B. SANFORD. 2003. Descent and modification of the overflow plume in the Denmark Strait. J. Phys. Oceanogr. 33: 1351-1364.

GORDON, A.L.; E. ZAMBIANCHI, A. ORSI, M.VISBECK, C.F. GIULIVI, T. WHITWORTH III and G. SPEZIE. 2004. Energetic plumes over the western Ross Sea continental slope. Geophys. Res. Lett. 31: L23102, doi:10.1029/2004GL020785.

GREGG, M.C. and E. ÖZSOY. 1999. Flow, water mass changes, and hydraulics in the Bosphorus. J. Geophys. Res. 107 (C3): 10.1029/2000JC000485.

GREGG, M.C. and E. ÖZSOY. 2002. Mixing on the Black Sea north of the Bosphorus. Geophys. Res. Lett. 26: 1869-1872.

KÄSE, R.H.; J.B. GIRTON and T.B. SANFORD. 2003. Structure and variability of the Denmark Strait overflow: model and observations. J. Geophys. Res. 108 (C6): 3181, doi:10.1029/2022JC001548.

LOFQUIST, K. 1960. Flow and stress near an interface between stratified fluids. Phys. Fluids, 3: 158-175.

MATT, S. and W.E. JOHNS. 2007. Transport and entrainment in the Red Sea outflow plume. J. Phys. Oceanogr. 37: 819-836.

MITSUDERA, H. and P.G. BAINES. 1994. Downslope gravity currents in a con- 


\section{Mixing in Downslope Flows in the Ocean - Plumes versus Gravity Currents / 419}

tinuously stratified environment: a model of the Bass Strait outflow. In: Proc. 11 th Australasian Fluid Mechanics Conference, Hobart, Australia, pp. 1017-1020.

MORTON, B.R.; G.I. TAYLOR and J.S. TURNER. 1956. Turbulent gravitational convection from maintained and instantaneous sources. Proc. Roy. Soc. Lond. A, 234: 1-23.

ÖZSOY, E.; Ü. ÜNLÜATA and Z. TOP. 1993. The evolution of Mediterranean water in the Black Sea: interior mixing and material transport by doublediffusive intrusions. Prog. Oceanogr. 31: 275-320.

PETERS, H. and W.E. JOHNS. 2005. Mixing and entrainment in the Red Sea outflow plume. Part II: turbulent characteristics. J. Phys. Oceanogr. 35: 584-600.

PETERS, H.; W.E. JOHNS, A.S. BOWER and D.M. FRATANTONI. 2005. Mixing and entrainment in the Red Sea outflow plume. Part I: plume structure. J. Phys. Oceanogr. 35: 569-583.

PETERS, H. and W.E. JOHNS. 2006. Bottom layer turbulence in the Red Sea outflow plume. J. Phys. Oceanogr. 36: 1763-1785.
PRICE, J.F.; M.O. BARINGER, R.G. LUECK, G.C. JOHNSON, I. AMBAR, G. PARILLA, A. CANTOS, M.A. KENNELLY and T. B. SANFORD. 1993. Mediterranean outflow mixing and dynamics. Science, 259: 1277-1282.

PRICE, J. F. and M.O. BARINGER. 1994. Outflows and deep water production by marginal seas. Prog. Oceanogr. 23: 161-200.

SIMPSON, J.E. 1997. Gravity Currents in the Environment and the Laboratory. Cambridge University Press, second edition, $244 \mathrm{pp}$

STRANG, E.J. and H.J.S. FERNANDO. 2001. Entrainment and mixing in stratified flows. J. Fluid Mech. 428: 349-386.

TURNER, J.S. 1973. Buoyancy Effects in Fluids. Cambridge University Press, $367 \mathrm{pp}$.

TURNER, J.S. 1986. Turbulent entrainment: the development of the entrainment assumption, and its application to geophysical flows. J. Fluid Mech. 173: 431-471.

WESSON, J.C. and M.C. GREGG. 1994. Mixing at Camarinal Sill in the Strait of Gibraltar. J. Geophys. Res. 99: 9847-9878. 